\section{Water-use efficiency declines during autumn leaf senescence in three deciduous tree species}

\author{
Adriana Sanchez, ${ }^{1}$ Nicole M. Hughes, ${ }^{2}$ \\ William K. Smith' \\ 'Department of Biology, Wake Forest \\ University, Winston-Salem, NC; \\ 2Department of Biology, High Point \\ University, High Point, NC, USA
}

\begin{abstract}
During fall leaf senescence in deciduous species, photosynthesis nears completion due to chlorophyll breakdown and re-assimilation. However, several other processes such as leaf nutrient uptake, re-translocation, and storage, or tissue dehydration to avoid frost damage, may be important and dependent upon stomatal opening. We report here on measured changes in photosynthesis $(A)$, leaf conductance to water vapor $(g)$, and WUE (estimated by $A / g$ ) in three deciduous tree species (Acer saccharum, Cornus florida, and Ginkgo biloba) during the weeks of leaf senescence preceding abscission. Substantial decreases in $A$ of 60 up to $80 \%$ were not matched quantitatively by similar declines in $g$ (40 to 70\%), resulting in corresponding decreases in WUE (estimated by $A / g$ ) from near $50 \%$ to over $300 \%$ among the three species. This shift to a lower WUE may reflect adaptive value in maintaining a higher $g$ relative to $A$ during the fall leaf senescence period.
\end{abstract}

\section{Introduction}

In numerous temperate species, fall leaf color change has been attributed to the degradation of chlorophyll and increasing exposure of carotenoids, although the de novo synthesis of anthocyanins has also been reported. ${ }^{1}$ This seasonal transition is characterized by degradation and mobilization of nitrogen-rich chloroplast stromal and thylakoid components that are translocated to storage tissues found in branches, twig, winter buds, bark, and roots. ${ }^{2,3}$ The translocation and storage of nitrogen during leaf senescence, enabling rapid remobilization for spring growth, is a recognized advantage in seasonally-deciduous tree species. ${ }^{4,5}$ In addition, a host of studies have now shown a tight coupling between stomatal opening, xylem, and phloem transport. ${ }^{6}$

Because photosynthetic capacity may be strongly correlated to leaf nitrogen content, ${ }^{7}$ it is not surprising that photosynthesis dimin- ishes as fall senescence and chlorophyll breakdown and processing progresses. It is also known that net photosynthetic capacity $(A)$ is strongly coupled to such factors as leaf conductance $(g)$ and the internal $\mathrm{CO}_{2}$ concentration in the leaf mesophyll $\left(C_{i}\right)$, leading to an optimization of the amount of $\mathrm{CO}_{2}$ gained per amount of transpired water $(E)$, i.e. leaf water use efficiency (WUE) in numerous species. ${ }^{8-10}$ Despite this optimization of WUE there are some instances in which stomatal opening and transpiration appear to be excessive, resulting in lower WUE. For example, excessive transpiration can act to cool leaves to well below warmer air temperature, ${ }^{11}$ or serve as a competitive strategy for acquiring soil water away from competing neighbors. ${ }^{9,12,13}$ In parasitic plants such as mistletoe, excessive transpiration may increase the rate of nutrient capture from their host and excessive transpiration during fall could also contribute to increased tissue dehydration ${ }^{14,15}$ - a potentially important feature for avoiding cellular frost damage during winter. ${ }^{16}$

Hypotheses about the adaptive advantages of leaf color change during fall senescence have been proposed, ${ }^{1}$ yet no study to our knowledge has focused on the $A, g$, and WUE relationship during this period that may last for weeks. The purpose of our study was to document changes in $\mathrm{A}, \mathrm{g}, \mathrm{Ci}$, and WUE during fall leaf senescence in three deciduous tree species and, especially, the possibility that stomatal closure lagged behind declines in net photosynthesis. Speculation about the adaptive significance of these changes is also presented.

\section{Materials and Methods}

We measured standard ecophysiological parameters $\left(A, g, C_{i}\right.$, and WUE) that occurred concomitantly with leaf senescence in fall. To estimate WUE, as well as to monitor stomatal behavior more explicitly, we used $A / g$ as a proxy for instantaneous $A / E$ (WUE), because $g$ typically has a strong linear, positive relationship with transpiration, ${ }^{6}$ as also found for our measurements $\left(R^{2} \geq 0.91\right.$, data not shown). Because WUE is calculated as $A / g$ and both have the same units, this parameter is unitless. All measurements were initiated when leaf color change was first noticed among the three selected species (Sept 25, 2011) and continued until senescence and leaf abscission were very near completion ( Nov 9 ).

The study was conducted using replicated trees found in a second-growth, mixed evergreen forest and cultivated trees located on the campus of Wake Forest University, NC, USA (36 $08^{\circ} 8.2^{\prime \prime} \mathrm{N}, 80^{\circ} 16^{\prime} 46.3$ " W; altitude $\sim 330 \mathrm{~m}$ ). Three deciduous tree species, Acer saccharum
Correspondence: Adriana Sanchez Department of Biology, Wake Forest University, Winston-Salem, NC 27109-7325, USA

Tel. +1.336.458.3915 - Fax: +1.336.758-6008.

E-mail: sancheza@wfu.edu

Key words: fall leaf senescence, leaf conductance, photosynthesis, water use efficiency.

Acknowledgments: we thank Joshua Winneberger (Wake Forest University) for help with data collection. This study was supported partially by the National Science Foundation, Physiological Systems and Structure Program.

Contributions: AS, data collection, manuscript preparation; NMH, experimental design, interpretation of data; WKS, experimental design, manuscript preparation.

Received for publication: 3 September 2012.

Revision received: 25 May 2013.

Accepted for publication: 5 June 2013.

This work is licensed under a Creative Commons Attribution NonCommercial 3.0 License (CC BYNC 3.0).

CC Copyright A. Sanchez et al., 2013

Licensee PAGEPress srl, Italy

International Journal of Plant Biology 2013; 4:e7 doi:10.4081/pb.2013.e7

Marshall, Cornus florida L., Ginkgo biloba L., were selected based on their abundance in the study area and measurements were taken on four mature, healthy appearing individuals of each species (except for $G$. biloba where two individuals were measured), over the entire period of initial leaf color change to abscission. Acer saccharum and $C$. florida are native to North Carolina, while $G$. biloba is native to East Asia and cultivated worldwide.

For 2-4 individuals of each of the three species, photosynthetic gas exchange of individual leaves was monitored for leaves on south to south-east facing sides of each tree, throughout the senescence period (first leaf color change to leaf abscission), approximately every week. All leaves used during the study were fully expanded and mature, and located on the 2nd to 5th node of each sampled stem.

All gas exchange parameters were measured using a Li-Cor LI-6400 portable photosynthesis system, at ambient temperature and $\mathrm{CO}_{2}$ concentration at $400 \mu \mathrm{mol} \mathrm{m} \mathrm{m}^{-2} \mathrm{~s}^{-1}$. To avoid effects due to variable ambient sunlight, the LED light source (6400-02B) was set at a photon flux density of $1500 \mu \mathrm{mol} \mathrm{m} \mathrm{m}^{-2} \mathrm{~s}^{-1}$, well above the light saturation point for maximum net photosynthesis, but not high enough to create photoinhibition (based on field measurements of light response curves; data not shown). Because individual leaves on the 
same tree often had variable colors, the sampling cuvette was placed on an area of the leaf with the dominant color. Acer saccharum and $C$. florida have leaf color changes from green to purple or light green, and then to red or yellow. Ginkgo biloba changed from green to light green and yellow. The temporal order of all leaf measurements among the three species was randomized throughout the study period.

Air temperatures during the sample period, were obtained from the nearby ( $\sim 4 \mathrm{~km})$ SmithReynolds Airport, Winston-Salem, NC. To minimize temperature effects on gas exchange, measurements were taken from 9-1030 hr (solar time) on warmer days and from 10-11:30 am following colder nights $\left(2-5^{\circ} \mathrm{C}\right)$. Vapor pressure deficits (VPD, difference between saturated and actual water vapor pressure) during the sampling period were also computed from air temperature and relative humidity data measured at the airport. ${ }^{17}$

Data were tested for statistical significance using either linear and non-linear regression analyses, according to best-fit criteria (greatest $\mathrm{R}^{2}$ values for slopes differing from zero). All slopes of best-fit regression curves were tested to determine if they differed from zero (no relationship) at $\mathrm{P}=0.01$ (ANOVA) and then tested for significant statistical difference (Zar 1999). Statistical tests and graphs were generated using Sigma Plot 11.0 (Systat Software Inc., Germany).

\section{Results and Discussion}

Although considerable variability occurred, mean temperatures for individual measurement days declined steadily over the study period with freezing air temperatures approached by the end of October and first of November. Maximum daily air temperatures varied from a high of $28.3^{\circ} \mathrm{C}$ (Sept 27) to a low of $10.1^{\circ} \mathrm{C}$ (Nov 9), while daily minimums ranged from a high of $23.1^{\circ} \mathrm{C}$ (Sept 25) to a low of $0.0 \mathrm{C}$ (Nov 1). Differences between daytime maximums and night minimums varied from between $10-15^{\circ} \mathrm{C}$ throughout the measurement period, while a general decline in air temperatures of about $15-20^{\circ} \mathrm{C}$ also occurred between the beginning and end of the study period. Vapor pressure deficit, although variable during the time of study, showed no consistent increase or decrease. On measurement days, a minimum of $0.41 \mathrm{kPa}$ and a maximum of $1.07 \mathrm{kPa}$ occurred.

There was a steady decline in net photosynthesis $(A)$ and leaf conductance $(g)$ as leaf senescence progressed in all three species (Figure 1A,B). The total percent change, estimated from the beginning to the end of the study, was more substantial in $A$ than in $g$ (data not shown). In Acer saccharum the per- cent change in $A$ was $77 \%$; for $C$. florida was $62 \%$, and in $G$. biloba $65 \%$. The percent change in $g$ for $A$. saccharum was $67 \%$, for $C$. florida was $41 \%$ and for $G$. biloba $58 \%$. By end of the study period, the lowest $g$ values recorded were near $20-30 \mathrm{mmol} \mathrm{m}^{-2} \mathrm{~s}^{-1}$. The leaf internal $\mathrm{CO}_{2}$ concentration (Ci) remained similar among all species and increased throughout the study period (Figure 1C). In G. biloba, consistently lower $C_{i}$ values mirrored the lower $g$ values (Figure 1B). Although $\mathrm{R}^{2}$ values were relatively low, all slopes were significantly different from zero ( $\mathrm{P}=0.01$, ANOVA).

WUE became asymptotic in $A$. saccharum and $C$. florida at $A$ between 4 to $5 \mu \mathrm{mol} \mathrm{m}{ }^{-2} \mathrm{~s}^{-1}$ (Figure 2A,B) and for Ginkgo at approximately $1.5 \mathrm{umol} \mathrm{m}^{-2} \mathrm{~s}^{-1}$ (Figure 2C). In A. saccharum, this threshold in WUE was about 0.1 (Figure 2A) and for $C$. florida $\sim 0.2$ (Figure 2B). Ginkgo biloba had a higher WUE threshold of approximately 0.1 (Figure 2C). Overall, WUE declined over the study period, although to varying degrees among the species (Figure 3A). The decrease in G. biloba was steep in the last three measurements, while in A. saccharum and $C$. florida the decrease was more steady.

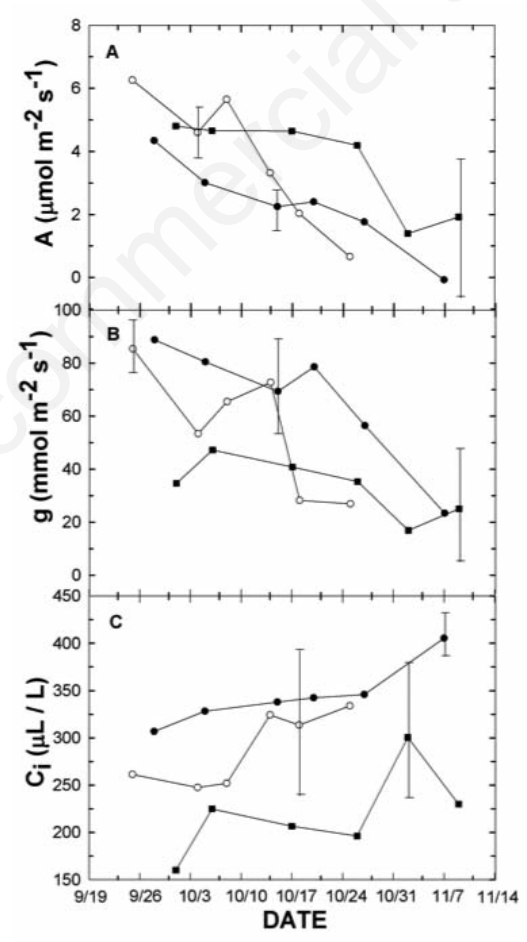

Figure 1. A-C) Mean net photosynthetic $\mathrm{CO}_{2}$ flux density $(A)$, leaf water vapor conductance $(g)$, and $\mathrm{CO}_{2}$ concentration inside the leaf mesophyll $\left(C_{i}\right)$ for all three species $[($ Acer saccharum $(\circ)$, Cornus florida $(\bullet)$, Ginkgo biloba $(-)$ ], during the time of the study. Vertical lines are the greatest (worst) standard error (SE) for each species curve. All slopes are significantly different from zero ( $\mathbf{P}=\mathbf{0 . 0 1}$, ANOVA).

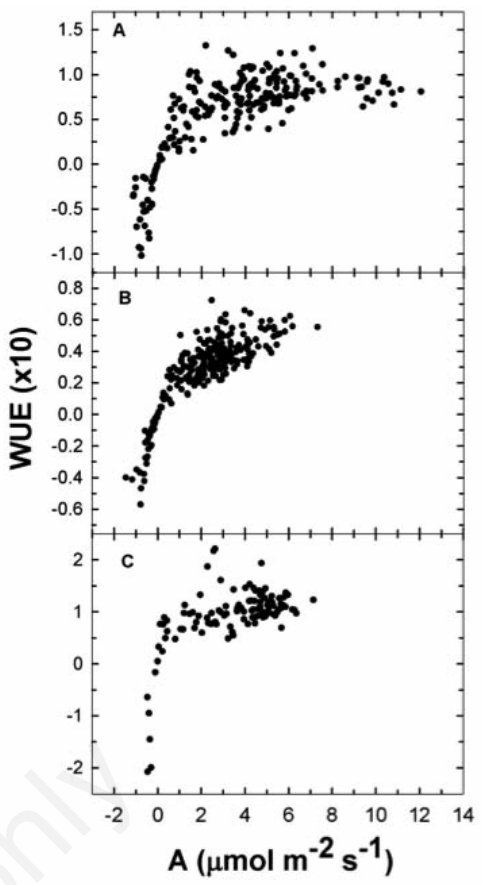

Figure 2. Relationship between net photosynthesis $(A)$ and $A / g$ (a proxy for WUE) for the three species in this study. A) Acer saccharum; B) Cornus florida; C) Ginkgo biloba. There are no units for WUE because it is calculated from the ratio of $A / g$ and both are expressed in the same units of measurement.

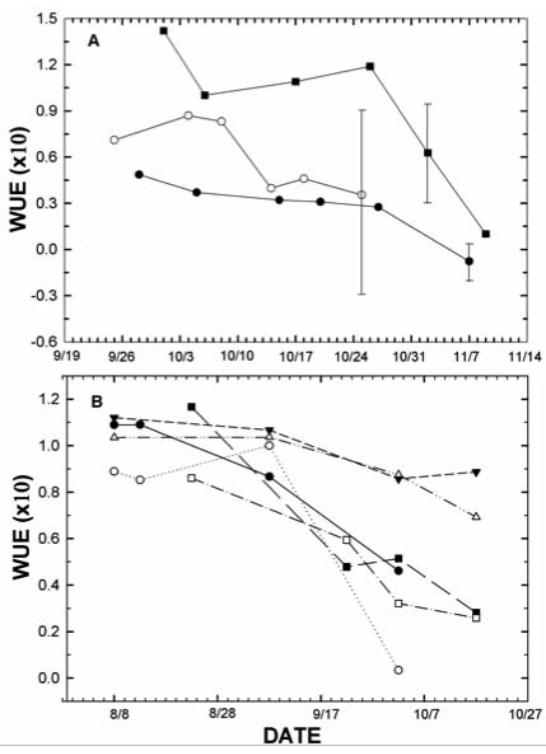

Figure 3. A) Changes in WUE (estimated from $A / g$ ) during the study period for the three species [(Acer saccharum $(\circ)$, Cornus florida (•), Ginkgo biloba (-)]. B) Literature data re-plotted from Grassi and Magnani (2005) for oak (Quercus robur; solid symbols) and ash (Fraxinus oxyphylla; open symbols) over three consecutive years $(2001=\circ ; 2002=\Delta ; 2003=\square)$. 
As described above, the decline in $g$ was greater than the corresponding decrease in $A$ over the length of the study period. Thus, the decline in WUE was due to a slower decline in $g$ relative to $A$. Autumn leaf senescence in deciduous species is often characterized by the gradual translocation of chlorophyll to storage tissue in different parts of the plant. ${ }^{2,3,18}$ In the present study, this loss of green coloration was, as expected, accompanied by a decrease in $A$ (Figure 1A). As leaf senescence progressed, there was also a general decline in $g$ and WUE, along with the expected increase in $C_{i}$ (Figures 1 and $3 \mathrm{~A}$ ). However, declines in $A$ were not mirrored by a corresponding stomatal closure, so that WUE decreased steadily even though $g$ also decreased. In fact, even after leaves had changed from green to almost completely red or yellow and $A$ was low or even negative (respiration outweighed $\mathrm{CO}_{2}$ assimilation; Figure 1A), stomata remained partially open, i.e. relatively high $g$ coinciding with an increase in $C_{i}$, and lower WUE (Figures 1 and 3A). The relationship between $A$ and WUE is corroborated in Figure 2A-C, where low values of $A$ and relatively high $g$ generated the lowest WUE values.

A large variety of plant species have been reported to coordinate their $\mathrm{CO}_{2}$ and water loss by tightly coupling photosynthesis and transpiration via a stomatal behavior pattern that can optimize water use efficiency, or $A / g .^{10,19}$ Although there are exceptions to this optimization strategy, e.g. cases of water competition, ${ }^{13}$ transpirational leaf cooling, ${ }^{11,12}$ or xylem tapping parasites, ${ }^{9,14,15}$ there have been no studies to our knowledge evaluating water use efficiency changes during fall leaf senescence in deciduous species. However, two previous studies have reported findings similar to our results whereby declining water use efficiency occurred in fall, but they did not consider specific changes in $A$ relative to $g$ (WUE). For example, Proietti found that during fall leaf senescence in Olea europaea chlorophyll content decreased with an accompanying reduction in net photosynthesis (see Figure 2 in Proietti). ${ }^{20}$ Leaf conductance $(g)$ also decreased, but held at more than $50 \mathrm{mmol} \mathrm{m}^{-2}$ $\mathrm{s}^{-1}$ when chlorophyll content was near $0 \mathrm{~g} \mathrm{~m}^{-2}$ (Figure 3 in Proietti). ${ }^{20}$ Proietti also reported an increase of $C_{i}$ as $A$ and chlorophyll content approached zero. Similar results were found by Grassi and Magnani in a three-year study on deciduous oak (Quercus robur) and ash (Fraxinus oxyphylla) trees, where there was a general decrease in $A$ by the end of the summer and beginning of the fall (their Figure 3 ). ${ }^{21}$ However, $g$ either increased or decreased depending on annual precipitation amounts. Somewhat paradoxically, $g$ sharply increased at the beginning of the fall following an extremely dry summer (their Figure 3). Taken from the published data in Grassi and Magnani, ${ }^{21}$ we re- plotted the relationship between day of the year and WUE, and found that WUE also decreased during fall but had an even greater decrease in the dryer than wetter years (Figure $3 \mathrm{~B})$. The findings of the two studies above corroborate the results presented here: leaves may not close their stomata so that WUE during fall leaf senescence is maintained or even increased. In addition, the results of Grassi and Magnani ${ }^{21}$ show that the driest year of their study also corresponded to the lowest WUE for the year.

\section{Conclusions}

In summary, the pattern measured here agrees in general, with other studies reporting a lowering of WUE during declining photosynthesis at the end of a summer growth period in several different deciduous species. ${ }^{20,21}$ One may speculate that the benefit of profligate stomatal opening and transpiration (lower WUE) is the enhancement of xylem flow and phloem translocation, insuring adequate nutrient re-assimilation, transport to storage organs, and uptake from the soil. However, the data reported here only describe the occurrence of excessive stomatal opening, in the sense that $g$ does not track $A$ (optimization) and WUE declines. Also, as leaf senescence is near completion and the abscission layer is formed, water loss from the leaf might not affect the plant's water balance and might benefit the subtending branches by avoiding frost damage. However, more studies are needed to determine the possible adaptive importance among species of delayed stomatal closure and lowered water use efficiency on nutrient reassimilation, uptake, and storage, plus freezing tolerance, in deciduous species. Additional studies may also determine if this pattern is characteristic, in general, of deciduous species

\section{References}

1. Archetti M, Döring TF, Hagen SB, et al. Unravelling the evolution of autumn colours: an interdisciplinary approach. Trends Ecol Evol 2009;24:166-73.

2. Matile P. Biochemistry of Indian summer: physiology of autumnal leaf coloration. Exp Gerontol 2000;35:145-58.

3. Fracheboud Y, Luquez V, Björkén L, et al. The control of autumn senescence in European Aspen. Plant Physiol 2009;149:1982-91.

4. Ougham HJ, Morris P, Thomas H. The colors of autumn leaves as symptoms of cellular recycling and defenses against environmental stresses. Curr Top Dev Biol 2005;
66:135-60.

5. Thomas H, Huang L, Young M, Ougham H. Evolution of plant senescence. BMC Evol Biol 2009;9:163.

6. Nobel PS. Physicochemical and environmental plant physiology. 4th ed. Oxford: Academic Press; 2009.

7. Yasumura Y, Hikosaka K, Hirose T. Seasonal changes in photosynthesis, nitrogen content and nitrogen partitioning in Lindera umbellata leaves grown in high or low irradiance. Tree Physiol 2006;26:131523.

8. Farquhar G, Sharkey T. Stomatal conductance and photosynthesis. Annu Rev Plant Physiol 1982;33:317-45.

9. Ehleringer JR. Variation in leaf carbon isotope discrimination in Encelia farinosa: implications for growth, competition, and drought survival. Oecologia 1993;95:340-46.

10. Drake BG, Gonzàlez-Meler MA. More efficient plants: a consequence of rising atmospheric C02? Annu Rev Plant Physiol Plant Mol Biol 1997;48:609-39.

11. Smith WK. Temperatures of desert plants: another perspective on the adaptability of leaf size. Science 1978;201:614-6.

12. Cook GD, Dixon JR, Leopold AC. Transpiration: its effects on plant leaf temperature. Science 1964;144:546-47.

13. Gordon DR, Welker JM, Menke JW, Rice KJ. Competition for soil water between annual plants and blue oak (Quercus douglasii) seedlings. Oecologia 1989;79:533-41.

14. Ehleringer JR, Schulze E-D, Ziegler H, et al. Xylem-tapping mistletoes: water or nutrient parasites? Science 1985;227:1479-81.

15. Escher P, Peuke AD, Bannister P, et al. Transpiration, C02 assimilation, WUE, and stomatal aperture in leaves of Viscum album (L.): effect of abscisic acid (ABA) in the xylem sap of its host (Populus $x$ euamericana). Plant Physiol Bioch 2008;46:64-70.

16. Pearce RS. Plant freezing and damage. Ann Bot 2001;87:417-24.

17. List RJ. Smithsonian metereological tables. Washington: Smithsonian Institution Press; 1987.

18. Keskitalo J, Bergquist G, Gardeström P, Jansson S. A cellular timetable of autumn senescence. Plant Physiol 2005;139:163548.

19. Cowan IR. Stomatal behaviour and environment. Adv Bot Res 1977;4:117-228.

20. Proietti P. Gas exchange in senescing leaves of Olea europaea L. Photosynthetica 1998;35:579-87.

21. Grassi G, Magnani F. Stomatal, mesophyll conductance and biochemical limitations to photosynthesis as affected by drought and leaf ontogeny in ash and oak trees. Plant Cell Environ 2005;28:834-49. 